\title{
Mediterranean Diet and physical activity in Romanian and Spanish university students - a comparative study
}

\author{
Badicu G. ${ }^{1 A B C D E}$, Chacón C.R. ${ }^{2 A B C D E}$, Zurita-Ortega F. ${ }^{3 A B C D E}$, Castro-Sanchez M. ${ }^{3 A B C D E}$, Balint L. ${ }^{1 A B C D E}$ \\ ${ }^{1}$ Department of Physical Education and Special Motility, Faculty of Physical Education and Mountain Sports, \\ Transilvania University of Braşov, Romania \\ ${ }^{2}$ Department of Research and Diagnosis Methods in Education, University of Granada, Granada, Spain \\ ${ }^{3}$ Department of Didactics of Musical, Plastic and Corporal Expression. University of Granada, Granada, Spain
}

Authors' Contribution: A - Study design; B - Data collection; C - Statistical analysis; D - Manuscript Preparation; E - Funds Collection.

\begin{abstract}
Purpose: $\quad$ The main purpose of this research was to show if there are differences between the Mediterranean diet and physical activity in students from Romania and Spain.

Material: $\quad$ The study was carried out on a sample of 567 participants, 149 of which (24.69\%) are from Romania (Transilvania University of Braşov) and 427 (75.31\%) are students from Spain (University of Granada). To evaluate adherence to the Mediterranean diet we used The Mediterranean Diet Quality Index (KIDMED), and for the assessment of the level of physical activity, we used the Physical Activity Questionnaire for Adolescents (PAQ-A). The reliability of the KIDMED was good (Cronbach's $\alpha=0.83$ ) and for PAQ-A is 0.874 . Statistical analyses were done through program IBM SPSS Statistics 22. The statistical indicators used in this study, were the following: standard deviation (SD), arithmetic average (X), chi-square test, Student's T-test (t), percent $\%$, Levene's test, ANOVA One-Way.

Results: $\quad$ The results of the variance analysis showed that there is no statistically significant relationship between the adherence to the Mediterranean diet and physical activity in Romanian students ( $F=0.517 ; p=0.598$ ), or in Spanish students $(\mathrm{F}=0.255 ; \mathrm{p}=0.775)$. Also, the results regarding adherence to the $\mathrm{MD}$ and $\mathrm{PA}$ was: poor adherence, $\mathrm{n}=31$, (mean $=29.06$; standard deviation $=3.723)$, average adherence, $\mathrm{n}=275$, (mean $=28.62$; standard deviation=3.386), and high adherence, $n=261$ (mean=28.50; standard deviation=3.779).

Conclusions: This study highlighted the fact that there are no significant differences regarding the adherence to the Mediterranean diet and the level of physical activity between the two countries (Romania and Spain). Unlike Spanish students, we found that Romanian students have a poor adherence to the MD.

Keywords: Mediterranean Diet, physical activity, students, questionnaire, physical education.
\end{abstract}

\section{Introduction}

It's believed that the Mediterranean Diet (MD) is one of the healthiest diets, given that, in the Mediterranean countries, the rate morbidity in conjunction with chronical diseases is lower and life expectancy is higher [1]. Also, the MD has a protective role in relation to: the development of Alzheimer's disease, the risk of heart attack, certain digestive disorders, certain tumors such as colorectal and breast tumors, diabetes and other pathologies associated with oxidative stress. This dietary model helps to improve body composition, favoring the decrease in the percentage of fat mass thanks to its low consumption in hypercaloric foods and foods rich in saturated fats [2].

As we all know, the MD is based on the consumption of foods grown in the Mediterranean region, which are very high in natural antioxidants. The MD is also based on fruits, olive oil, cereals, grain legumes and vegetables, a moderate consumption of eggs, fish and dairy products [3].

If it is kept according to its basic principles, the MD should deliver results from the first week, these being very visible in the level of muscle tone and positive energy. Persons who care on MD feel, from the first days, a state of well-being characterized by overflowing energy and high resistance to stress factors or fatigue.

\footnotetext{
(c) Badicu G., Chacón C.R., Ortega F.Z., Sánchez M.C., Balint L., 2019 doi:10.15561/20755279.2019.0402
}

The prevalence of the adherence to the MD was often the object of examination in Mediterranean countries, in young adults [4-6]. For example, the prevalence of a poor or non-existent adherence to the MD was $21.8 \%$ in students from Cyprus, and 3.1\% and $9.5 \%$ in students from Spain [7]. Furthermore, this subject was also studied in countries with linguistic and cultural influence, like Brazil [8], Chile [9, 10], or the South of the United States [11]. Sadly, in Romania, the MD was not an important subject, and there are few studies on this matter therefore [12]. The Bloomberg Agency has published a list of the top 56 ranked states, which uses MD, but, unfortunately, Romania does not appear, instead, we can meet some Eastern European countries: like Greece, which is ranked 26th, Montenegro, on the 41st place, Bosnia Herzegovina, 42th place or Albania, which we find in the 43rd position [13]. According to the same study Spain is the leader of this ranking, in terms of MD. It is considered that MD and the public health system make Spain the healthiest country in the world [13].

In addition to following a healthy diet it is well known that consistent physical activity (PA), as well the exercises, can have immediate or long-term benefits on health [14-16].

According to the last regulatory guidelines for physical activity (PA), and taking into account its many health benefits, WHO recommends $150 \mathrm{~min}$ of moderate- 
intensity aerobic PA [17-19], 75 min of vigorous-intensity aerobic PA [20-22], or an equivalent combination of moderate-intensity and vigorous-intensity activities.

Research shows that regular PA can lead to a lower risk of diseases and to an improvement of the general quality of life [23-25].

Recent studies showed that students do not meet the general recommendations in relation to PA levels [2628]. Following these studies, it has been concluded that students were less active than children and teenagers.

Pavicic et al. (2019) concluded that a high level of PA was associated with the MD, but not in a significant manner [29]. The variables associated with a high level of PA were male gender, younger age, normal WHR (waistto-hip ratio), non-sedentary occupation and reduced sitting time [29].

Another study, carried out by Zurita-Ortega et al., on 597 students from Ceuta, Melilla, and Granada (Spain), showed that there is a relationship between MD adherence, $\mathrm{PA}$, self-concept, and other socio-demographic factors [30]. For the respondents which showed a high level of PA, $82.3 \%$ they had high adherence to the MD, with $17.7 \%$ having an average adherence. Among the students that did not do PA, 25.7\% also had average adherence to the MD. It has shown that the university campus was associated with the level of adherence to the MD, with adherence being lowest in Melilla and Ceuta [30].

Thus, in line with the ideas brought forward, the purpose of this study was to make a comparative analysis between the MD and PA, in students from Romania and Spain.

\section{Material and methods}

Participants: The research was carried out in March - May 2018, on a number of 580 students, 166 from Romania and 427 from Spain. Of the participants 13 did not fulfil the eligibility criteria (questionnaires that were incomplete, some failed to return the informed consent forms) and they were not included therefore. Finally, the last sample consisted of 567 participants: 149 students (24.69\%) from Romania (Transilvania University of Braşov) and 427 (75.31\%) students from Spain(University of Granada).

\section{Research Design.}

Instruments

The first instrument used in this research was The Mediterranean Diet Quality Index (KIDMED) [31], which measured the level of adherence to the MD. The questionnaire comprised 16 items with reference to Mediterranean dietary models. Four items denote negative connotations with respect to the MD (e.g., do you eat sweets daily?) and are scored as a -1 , while twelve items refer to positive connotations (e.g., do you use olive oil for cooking at home?) and are scored as a +1 [2]. The summation of the questionnaire items produces a total score, which varies from -4 to 12 . The interpretation values of MD are as follows: high ( $\geq 8)$, average (2-7) or poor $(\leq 1)$. In our study, the reliability of the KIDMED was good (Cronbach's $\alpha=0.83$ ).
To measure the level of PA we used the Physical Activity Questionnaire for Adolescents (PAQ-A). This questionnaire contains 10 items and the assessment was based on a five-point Likert scale. This instrument requires a report being provided by the participants, regarding the frequency and type of physical activity done on each of the seven days prior to the use of this questionnaire. The individual items are gathered and creates a variable that describes the general levels of PA. A score of 1 indicates low PA, whereas a score of 5 indicates high PA [3]. PAQ-A demonstrates reliable psychometric properties by using alfa Cronbach's $(\alpha=0.874)$ [3].

\section{Procedure}

Subjects involved in this study received more detailed explanations of this research.

The Mediterranean Diet Quality Index (KIDMED) and Physical Activity Questionnaire for Adolescents (PAQ-A) were administered during theoretical classes held by professors, in the second semester of the academic year 2017-2018, in the period mentioned.

Before applying the interview, and following the test protocol and the explanation as clear as possible of the objective, all participants had given their written informed consent for participation. Subjects complied with Ethical principles of the Declaration of Helsinki and ethical approval was granted by the Ethics Committee of the University of Transilvania.

\section{Statistical Analysis}

Statistical analyses were carried out using the program IBM SPSS Statistics 22 (Armonk, NY, USA). The statistical indicators used in this research, were the following: standard deviation (SD), arithmetic average (X), chi-square test, Student's T-test (t), percent $\%$, Levene's test, ANOVA One-Way. The chi-square test was used to determine if there is a statistically significant difference between the country of origin and adherence to the MD. The calculation of the chi-square statistic started from the following hypotheses: Hypothesis $\mathrm{H} 0=$ There is no statistically significant association between the two variables (country of origin and adherence to MD) and Hypothesis $\mathrm{H} 1$ = there is a statistically significant association between the two variables. The T-test was used on independent samples to compare the average values of PA in the two groups of students (Romanian and Spanish) were highlighted by estimating the variances of the two groups with Levene's test. The hypotheses of Levene's test, was: $\mathrm{H} 0$ (null hypothesis) = The variances of the two groups are homogenous and, $\mathrm{H} 1=$ The variances of the two groups are heterogeneous. The hypotheses of the T test, was: H0: There is no significant difference between students from the two countries, in terms of PA and, H1: There is a significant difference between students from the two countries, in terms of PA. Last but not least, in order to establish if there is a significant link between the adherence to the MD and PA in students taking part in this study, we used the one-way analysis of variance or the One-Way ANOVA. 


\section{Results}

According to gender from the total sample studied, adherence to the average MD shows the highest percentage values. Male subjects are those who present a poor adherence to MD. Also, the average level of PA shows the values close to both sexes (Table 1).

Of the students with poor adherence to the MD, most $(90.3 \%)$ are from Romania. Of all Romanian students, $20 \%$ have a poor adherence to the MD, compared to the much smaller percentage of $0.7 \%$ of the Spanish students, with the same level of adherence.

As far as the average adherence to the MD is concerned, $47.9 \%$ of Romanian students and $47.7 \%$ of
Spanish students fall into this category.

Regarding the high adherence to the MD, only $32.1 \%$ of the Romanian students have this level of MD adherence, whereas no less than $50.6 \%$ of the Spanish students have a high adherence (Table 2 ).

It was found that the there is indeed a significant link between the two variables $\left(\chi^{2}=79.618\right.$; $\left.\mathrm{df}=2, \mathrm{p}<0.001\right)$. More specifically, students from Romania have a lower adherence to MD than students from Spain. Cramer's $\mathrm{V}$ coefficient (Cramer's $\mathrm{V}=0.375$ ) shows an averagely intensive association between the two variables. Results confirm the first hypothesis (Table 3 ).

Table 1. Characteristics of the MD and PA based on gender

\begin{tabular}{lllll}
\hline \multirow{2}{*}{ Characteristics } & & Gender & & Total \\
& & male & female & $5.5 \%(n=31)$ \\
\multirow{2}{*}{ KIDMED } & Poor adherence & $32.3 \%(n=10)$ & $67.7 \%(n=21)$ & $5 \%(n=275)$ \\
& Average adherence & $59.6 \%(n=164)$ & $40.4 \%(n=111)$ & $48.5 \%(n)$ \\
Physical activity & & $67.4 \%(n=176)$ & $32.6 \%(n=85)$ & $46.0 \%(n=261)$ \\
& High adherence & $\mathrm{M}=28.46 \mathrm{SD}=3.57$ & $\mathrm{M}=28.79 \mathrm{SD}=3.59$ & $\mathrm{M}=28.59 \mathrm{SD}=3.58$ \\
\hline
\end{tabular}

KIDMED, Mediterranean Diet Quality Index; PA, Physical Activity.

Table 2. KIDMED depending on the country of origin

\begin{tabular}{|c|c|c|c|c|c|}
\hline \multirow{2}{*}{\multicolumn{2}{|c|}{ Characteristics }} & & \multicolumn{2}{|c|}{ Country of origin } & \multirow{3}{*}{$\begin{array}{l}\text { Total } \\
31\end{array}$} \\
\hline & & & \multirow{2}{*}{$\begin{array}{l}\text { Romania } \\
28\end{array}$} & \multirow{2}{*}{$\frac{\text { Spain }}{3}$} & \\
\hline \multirow{12}{*}{ KIDMED } & \multirow{4}{*}{ Poor adherence } & Count & & & \\
\hline & & \% within KIDMED & $90.3 \%$ & $9.7 \%$ & $100,0 \%$ \\
\hline & & $\%$ within Country of origin & $20.0 \%$ & $0.7 \%$ & $5,5 \%$ \\
\hline & & $\%$ of Total & $4.9 \%$ & $0.5 \%$ & $5,5 \%$ \\
\hline & \multirow{4}{*}{ Average adherence } & Count & 67 & 208 & 275 \\
\hline & & \% within KIDMED & $24.4 \%$ & $75.6 \%$ & $100,0 \%$ \\
\hline & & $\%$ within Country of origin & $47.9 \%$ & $48.7 \%$ & $48,5 \%$ \\
\hline & & $\%$ of Total & $11.8 \%$ & $36.7 \%$ & $48,5 \%$ \\
\hline & \multirow{4}{*}{ High adherence } & Count & 45 & 216 & 261 \\
\hline & & \% within KIDMED & $17.2 \%$ & $82.8 \%$ & $100,0 \%$ \\
\hline & & $\%$ within Country of origin & $32.1 \%$ & $50.6 \%$ & $46,0 \%$ \\
\hline & & $\%$ of Total & $7.9 \%$ & $38.1 \%$ & $46,0 \%$ \\
\hline \multirow{4}{*}{\multicolumn{2}{|c|}{ Total }} & Count & 140 & 427 & 567 \\
\hline & & \% within KIDMED & $24,7 \%$ & $75.3 \%$ & $100.0 \%$ \\
\hline & & $\%$ within Country of adherence & $100,0 \%$ & $100.0 \%$ & $100.0 \%$ \\
\hline & & $\%$ of Total & $24,7 \%$ & $75.3 \%$ & $100.0 \%$ \\
\hline
\end{tabular}

Table3. Results of the Chi-Square test and of Cramer's $V$ coefficient in relation to the country of origin and adherence to $\mathrm{MD}$

\section{Chi-Square Tests}

\begin{tabular}{llll}
\hline variables & Value & df & Asymp. Sig. (2-sided) \\
\hline Pearson Chi-Square & 79.618 & 2 & .000 \\
N of Valid Cases & 567 & & \\
Symmetric Measures & & \\
variables & Value & Approx. Sig. \\
Cramer's V & .375 & .000 \\
$\mathrm{~N}$ of Valid Cases & 567 & & \\
\hline
\end{tabular}


If $\mathrm{p}>\alpha(0.05), \mathrm{H} 0$ is accepted (variances are equal), and the results on the second line of the $\mathrm{T}$ test table are listed. If $\mathrm{p}<\alpha, \mathrm{H} 1$ is accepted (variances are unequal), and the listing of results on the second line of the T test table is continued.

Because $\mathrm{p}=0.940, \mathrm{H} 0$ is accepted, i.e. there are no significant differences between students from the two countries, as far as PA is concerned (Table 4).

The results of the Anova One-Way analysis showed that there is no statistically significant difference between students with different levels of adherence to $\mathrm{MD}$, in relation to $\mathrm{PA}(\mathrm{F}=0.365 ; \mathrm{p}=0.695)$.

Thus, the average level of PA on students with a poor adherence to MD is 29.06, the average level of PA on students with average adherence to MD is 28.62, whereas those with a high adherence to MD have a level of PA of

\subsection{0 (Table 5).}

It has been verified if there is a statistically significant relationship between adherence to the MD and PA in students from Romania and Spain. The two groups of students were observed separately.

The results of the analysis of variance showed that there is no statistically significant relationship between adherence to the MD and PA in Romanian students, $(\mathrm{F}=0.517 ; \mathrm{p}=0.598)$, or in Spanish students $(\mathrm{F}=0.255$; $\mathrm{p}=0.775$ ) (Table 6).

\section{Discussions}

The main purpose of this research was to carry out a comparative analysis of the MD and PA, in students from Romania and Spain. There are few studies that analyze dietary habits and PA based on country of origin, especially

Table 4. Average values of PA for Romanian and Spanish students

\title{
Independent Samples Test
}

\author{
Levene's Test \\ for Equality of t-test for Equality of Means \\ Variances
}

Characteristics

$\begin{array}{lllll} & \text { Sig. } & \text { Mean } & \text { Std. Error } & \begin{array}{l}\text { 95\% Confidence } \\ \text { Interval of the }\end{array} \\ \text { (2-tailed) Difference } & \text { Difference } & \text { Difference }\end{array}$

\begin{tabular}{|c|c|c|c|c|c|c|c|c|c|c|}
\hline & & & & & & & & & Lower & Upper \\
\hline PHYSICAL & $\begin{array}{l}\text { Equal } \\
\text { variances } \\
\text { assumed }\end{array}$ & .001 & .974 & .075 & 565 & .940 & .026 & .350 & -.660 & .713 \\
\hline ACTIVITY & $\begin{array}{l}\text { Equal } \\
\text { variances no } \\
\text { assumed }\end{array}$ & & & .076 & 237.797 & .940 & .026 & .349 & -.661 & .713 \\
\hline
\end{tabular}

Table 5. Results regarding adherence to the MD and PA for all students involved in the study

\section{PHYSICAL ACTIVITY}

\begin{tabular}{|c|c|c|c|c|c|c|c|c|}
\hline Characteristics & $\mathbf{N}$ & Mean & Std. De & Std. Error & $\begin{array}{l}\text { 95\% Confiden } \\
\text { for Mean } \\
\text { Lower Bound }\end{array}$ & $\begin{array}{l}\text { Ace Interval } \\
\text { Upper } \\
\text { Bound }\end{array}$ & Minimum & Maximum \\
\hline Poor adherence & 31 & 29.06 & 3.723 & .669 & 27.70 & 30.43 & 22 & 37 \\
\hline Average adherence & 275 & 28.62 & 3.386 & .204 & 28.22 & 29.02 & 17 & 37 \\
\hline High adherence & 261 & 28.50 & 3.779 & .234 & 28.04 & 28.96 & 17 & 37 \\
\hline Total & 567 & 28.59 & 3.586 & .151 & 28.29 & 28.88 & 17 & 37 \\
\hline
\end{tabular}

Table 6. Results of the analysis of variance on adherence to the MD and PA, for students from Romania and Spain

ANOVA

PHYSICAL ACTIVITY

\begin{tabular}{lllllll}
\hline Country of origin & & Sum of Squares & df & Mean Square & F & P \\
\hline \multirow{4}{*}{ Romania } & Between Groups & 13.305 & 2 & 6.652 & 0.517 & 0.598 \\
& Within Groups & 1764.088 & 137 & 12.877 & & \\
& Total & 1777.393 & 139 & & \\
\multirow{3}{*}{ Spain } & Between Groups & 6.610 & 2 & 3.305 & 0.255 & 0.775 \\
& Within Groups & 5495.353 & 424 & 12.961 & & \\
\hline
\end{tabular}


for Romania and Spain. This geographical location, which comes with a different climate and cultural customs, does not enable the cultivation of many of the typical foods of the Mediterranean basin (that constitute the MD) in Romania [14, 15]. Nevertheless, our study highlighted the fact that there are no significant differences between the two countries, in relation to adherence to the MD and physical PA. Most of Romanian students have a poor adherence to the MD. As far as average adherence to the MD is concerned, percentages for both Romanian and Spanish students are relatively the same. As regards a high adherence to the MD, Spanish students score higher than Romanian students, but not very high or significant. A recent study, carried out by González-Valero et al., on a sample of 775 students, showed an association between the MD, PA and motivational climate. This research points out the fact that the Ego-climate (EC) is related to a high adherence to the MD. The reason for this is that food is a key factor in performance and rivalry between members. Also, the future teachers of Physical Education, who manifest motivational processes based on their own satisfaction and on the fun, have low levels of adherence to the MD. At the same time, the authors have noted that effort and personal improvement are directly associated with adherence to MD [32]. Additionally, another study conducted on 400 workers in Croatia showed that onethird of the participants were highly physically active and they adhered to the MD. Significant variables associated with a high level of PA were gender $(\mathrm{p}<0.001)$, age ( $\mathrm{p}$ $=0.02)$, waist-to-hip ratio (WHR) $(\mathrm{p}<0.001)$, sitting time $(\mathrm{p}=0.044)$ and occupational type $(\mathrm{p}<0.001)$ [29]. Another study, which analyzes Physical Fitness and the Mediterranean Diet on 13 to 16-year old Icelandic students, shows medium/high levels of health-related physical fitness, with the girls obtaining slightly higher results. The participants' adherence to MD is classified as medium/high since $60 \%$ of the participants have a middle level and almost $25 \%$ have a high level [33].

Our study presented very similar values between the two countries of origin, as far as both the MD and PA are concerned. The only difference lies in the slightly poorer adherence to the MD of Romanian students, compared with Spanish students. For all the participants $(n=567)$ involved in this research, the results regarding adherence to the MD and PA was: poor adherence, $\mathrm{n}=31$, (mean $=29.06$; standard deviation=3.723), average adherence, $\mathrm{n}=275, \quad($ mean $=28.62 ; \quad$ standard deviation $=3.386)$, and high adherence, $\mathrm{n}=261$ (mean $=28.50$; standard deviation=3.779).

Our study has several limitations. First, the very low number of Romanian students, compared to the number of Spanish students. The attendance rate of Romanian students was quite low while our study was being carried out, and, also, many of them did not wish to fill in the questionnaires. Furthermore, the low number of Romanian students is determined as well by the tuition figures of the Faculty, for each study program. Even under these conditions the results of the study revealed that there are no significant differences between the two countries. It is true that the number of Spanish students included in the research was higher than that of the Romans and may have been observed in the results of the study.

After a thorough revision of the literature, we can safely say that this is one of the few studies on the subject of MD and level of PA on students from Romania.

\section{Conclusions}

Our research highlighted the fact that there are no significant differences between the two countries of origin, as far as adherence to the MD and level of PA are concerned. Unlike Spanish students, we found that Romanian students have a poor adherence to the MD. In the case of average adherence to the $\mathrm{MD}$, values are similar both for Romanian students, and Spanish students, and, Spanish students have higher scores than Romanian students when it comes to a high MD adherence. Additionally, the results of this research showed that there is no significant difference between students, with all levels of MD adherence, in terms of PA.

\section{Author Contributions:}

G.B., R.C.-C., F.Z.-O., L.B. and M.C.-S. conceived the hypothesis of this study. G.B. and R.C.-C. participated in data collection. G.B. and L.B. analyzed the data. All authors contributed to data interpretation of the statistical analysis. L.B., F.Z.-O., M.C.-S. and R.C.-C wrote the paper with significant input from G.B. All authors read and approved the final manuscript.

\section{Conflict of interests}

The author declares that there is no conflict of interests. 


\section{References}

1. Serra-Majem L, Ribas L, Ngo J, Ortega RM, García A, Pérez-Rodrigo C, et al. Food, youth and the Mediterranean diet in Spain. Development of KIDMED, Mediterranean Diet Quality Index in children and adolescents. Public Health Nutrition, 2004;7:931-5. https://doi.org/10.1079/PHN2004556

2. Kavouras SA, Panagiotakos DB, Pitsavos C, Chrysohoou C, Arnaoutis G, Skoumas Y, et al. Physical Activity and Adherence to Mediterranean Diet Increase Total Antioxidant Capacity: The ATTICA Study. Cardiology Research and Practice, 2011;2011:1-7. https://doi.org/10.4061/2011/248626

3. Lucia Maria L, Ovidiu S, Lencu C, Laza V. Dietary patterns, physical activity, body mass index, weightrelated behaviours and their interrelationship among Romanian university students-trends from 2003 to 2016. Nutrición Hospitalaria, 2018;35(2):375-383. https://doi.org/10.20960/nh.1296

4. Hadjimbei E, Botsaris G, Gekas V, Panayiotou AG. Adherence to the Mediterranean Diet and Lifestyle Characteristics of University Students in Cyprus: A Cross-Sectional Survey. Journal of Nutrition and Metabolism, 2016;2016:1-8. https://doi.org/10.1155/2016/2742841

5. Navarro-González, I, López-Nicolás, R, Rodríguez-Tadeo, A, Ros-Berruezo, G, Martínez-Marín, M, DomenéchAsensi, G. Adherence to the Mediterranean diet by nursing students of Murcia (Spain). Nutr. Hosp. 2014; 30: 165-172. https://doi.org/10.3305/nh.2014.30.1.7413

6. Durá-Travé T, Castroviejo Gandarias A. Adherence to a Mediterranean diet in college population. Nutr. Hosp. 2011; 26: 602-608. https://doi.org/10.3305/nh.2011.26.3.4891

7. Štefan L, Prosoli R, Juranko D, Čule M, Milinović I, Novak D, et al. The Reliability of the Mediterranean Diet Quality Index (KIDMED) Questionnaire. Nutrients, 2017;9:419. https://doi.org/10.3390/nu9040419

8. Dare C, Viebig RF, Batista NS. Body composition and components of Mediterranean diet in Brazilian and European University Students. Rev. Bras. Obes. Nutr. Emag. 2017; 11: 557-566.

9. Rodríguez FJ, Espinoza LR, Gálvez J, Macmillan NG, Solis P. Nutritional status and lifestyles in university students of the Pontificia Universidad Católica de Valparaiso. Rev. Univ. Salud. 2013; 15:123-135.

10.Darmon N, DrewnowskiA. Contribution of food prices and diet cost to socioeconomic disparities in diet quality and health: A systematic review and analysis. Nutr. Rev. 2015; 73: 643-660. https://doi.org/10.1093/nutrit/nuv027

11.Bottcher MR, Marincic PZ, Nahay KL, Baerlocher BE, Willis AW, Park J. Nutrition knowledge and Mediterranean diet adherence in the southeast United States: Validation of a field-based survey instrument. Appetite, 2017; 111:166-176. https://doi.org/10.1016/j.appet.2016.12.029

12.Chacón-Cuberos R, Badicu G, Zurita-Ortega F, CastroSánchez M. Mediterranean Diet and Motivation in Sport: A Comparative Study Between University Students from Spain and Romania. Nutrients, 2018;11:30. https://doi.org/10.3390/nu11010030

13.Chiujdea M. Dieta mediteraneană și sistemul public de sănătate fac din Spania cea mai sănătoasă țară din lume [The Mediterranean diet and the public health system make Spain the healthiest country in the world]. [Internet]. [updated 2018 Jun 15; cited 2019 May 22]. Available from: https://www. rfi.ro/social-109806-spania-sanatoasa-dieta-mediteraneana- sistem-public-sanatate (In Spanish)

14.Mandolesi L, Polverino A, Montuori S, Foti F, Ferraioli G, Sorrentino P, et al. Effects of Physical Exercise on Cognitive Functioning and Wellbeing: Biological and Psychological Benefits. Frontiers in Psychology, 2018;9:509. https://doi.org/10.3389/fpsyg.2018.00509

15.Rausch Osthoff A-K, Juhl CB, Knittle K, Dagfinrud $\mathrm{H}$, Hurkmans E, Braun $\mathrm{J}$, et al. Effects of exercise and physical activity promotion: meta-analysis informing the 2018 EULAR recommendations for physical activity in people with rheumatoid arthritis, spondyloarthritis and hip/knee osteoarthritis. RMD Open, 2018;4:e00713. https://doi.org/10.1136/rmdopen-2018-000713

16. Macpherson H, Teo W-P, Schneider LA, Smith AE. A Life-Long Approach to Physical Activity for Brain Health. Frontiers in Aging Neuroscience, 2017;9:147. https://doi.org/10.3389/fnagi.2017.00147

17.Krüger M, Seng C. Effects of Short Practice of Climbing on Barriers Self-Efficacy within a Physical Education and Sport Intervention in Germany. Sports, 2019; 7:81. https://doi.org/10.3390/sports7040081

18.Olanrewaju O, Kelly S, Cowan A, Brayne C, Lafortune L. Physical Activity in Community Dwelling Older People: A Systematic Review of Reviews of Interventions and Context. PLoS ONE, 2016. 11(12): e0168614. https://doi.org/10.1371/journal.pone.0168614

19.BădicuG.PhysicalActivityandHealth-RelatedQualityofLifein Adults from Braşov, Romania. Education Sciences, 2018;8:52. https://doi.org/10.3390/educsci8020052

20.World Health Organization. Global Recommendations on Physical Activity for Health. 2010. [Internet]. [updated 2018 Jun 15; cited 2019 March 12]. Available from: https://www. who.int/news-room/fact-sheets/detail/physical-activity

21.Hervás G, Ruiz-Litago F, Irazusta J, Fernández-Atutxa A, Fraile-BermúdezA.B,ZarrazquinI.PhysicalActivity,Physical Fitness, Body Composition, and Nutrition Are Associated with Bone Status in University Students. Nutrients, 2018; 10: 61. https://doi.org/10.3390/nu10010061

22.Zurita-Ortega F, Roman-Mata SS, Chacon-Cuberos R, Castro-Sanchez M, Muros JJ. Adherence to the Mediterranean Diet Is Associated with Physical Activity, Self-Concept and Sociodemographic Factors in University Student. Nutrients, 2018; 10:1-11. https://doi.org/10.3390/nu10080966

23.Badicu G. Physical Activity and Sleep Quality in Students of the Faculty of Physical Education and Sport of Braşov, Romania. Sustainability, 2018; 10:2410. https://doi.org/10.3390/su10072410

24.Cocca A, Liukkonen J, Mayorga-Vega D, Viciana-Ramírez J. Health-Related Physical Activity Levels in Spanish Youth and Young Adults. Perceptual and Motor Skills, 2014;118:247-60. https://doi.org/10.2466/10.06.PMS.118k16w1

25.Pengpid S, Peltzer K, Kassean HK, Tsala Tsala JP, Sychareun V, Müller-Riemenschneider F. Physical inactivity and associated factors among university students in 23 low-, middle- and high-income countries. International Journal of Public Health, 2015;60:539-49. https://doi.org/10.1007/s00038-015-0680-0

26.Varela-Mato V, Cancela, JM, Ayan, C, Martín, V, Molina, A. Lifestyle and Health among Spanish University Students: Differences by Gender and Academic Discipline. Int J Environ Res Public Health. 2012; 9: 2728-2741. https://doi.org/10.3390/ijerph9082728

27. Ortenburger DE, Wąsik J. Cognitive-behavioral approach and the role of physical activity in the treatment of musculoskeletal 
pain in athletes. Society integration education. Proceedings of the International Scientific Conference, 2018;4:182-189. https://doi.org/10.17770/sie2018vol1.3179

28.McPhee JS, French DP, Jackson D, Nazroo J, Pendleton N, Degens H. Physical activity in older age: perspectives for healthy ageing and frailty. Biogerontology, 2016;17:567-80. https://doi.org/10.1007/s10522-016-9641-0

29.Pavičić ŽS, Kenđel JG, Krešić G. The association between the Mediterraneandietandhighphysicalactivityamongtheworking population in Croatia. Medycyna Pracy. 2019; 70(2):169-176. https://doi.org/10.13075/mp.5893.00773

30.Zurita-Ortega F, San Román-Mata S, ChacónCuberos R, Castro-Sánchez M, Muros J. Adherence to the Mediterranean Diet Is Associated with Physical Activity, Self-Concept and Sociodemographic Factors in University Student. Nutrients, 2018;10:966. https://doi.org/10.3390/nu10080966
31.Godos J, Castellano S, Marranzano M Adherence to a Mediterranean Dietary Pattern Is Associated with Higher Quality of Life in a Cohort of Italian Adults. Nutrients, 2019;11:981. https://doi.org/10.3390/nu11050981

32.González-Valero G, Ubago-Jiménez JL, Ramírez-Granizo IA, Puertas-Molero P. Association between Motivational Climate, Adherence to Mediterranean Diet, and Levels of Physical ActivityinPhysicalEducationStudents.Behav.Sci.2019;9:37. https://doi.org/10.3390/bs9040037

33.Galan-Lopez P, Ries F, Gisladottir T, Domínguez R, Sánchez-Oliver AJ. Healthy Lifestyle: Relationship between Mediterranean Diet, Body Composition and Physical Fitness in 13 to 16-Years Old Icelandic Students. Int. J. Environ. Res. Public Health, 2018; 15: 2632. https://doi.org/10.3390/ijerph15122632

\section{Information about the authors:}

Badicu G.; (Corresponding author); http://orcid.org/0000-0003-4100-8765; georgian.badicu@unitbv.ro; Department of Physical Education and Special Motility, Faculty of Physical Education and Mountain Sports, University Transilvania of Braşov; 500068 Braşov, Romania.

Chacón C.R.; http://orcid.org/0000-0003-0937-1089; rchacon@ual.es; Department of Research and Diagnosis Methods in Education, University of Granada; 18071 Granada, Spain.

Zurita-Ortega F.; http://orcid.org/0000-0002-1189-894X; felixzo@ugr.es; Department of Didactics of Musical, Plastic and Corporal Expression. University of Granada; 18071 Granada, Spain.

Castro-Sanchez M.; https://orcid.org/0000-0002-2357-3093; manuelcs@ugr.es; Department of Didactics of Musical, Plastic and Corporal Expression. University of Granada; 18071 Granada, Spain.

Balint L.; http://orcid.org/0000-0003-3503-6233; balintlorand371@gmail.com; Department of Physical Education and Special Motility, Faculty of Physical Education and Mountain Sports, University Transilvania of Braşov; 500068 Braşov, Romania.

\section{Cite this article as:}

Badicu G, Chacón CR, Zurita-Ortega F, Castro-Sanchez M, Balint L. Mediterranean Diet and physical activity in Romanian and Spanish university students - a comparative study. Physical education of students, 2019;23(4):172-178.

https://doi.org/10.15561/20755279.2019.0402

This is an Open Access article distributed under the terms of the Creative Commons Attribution License, which permits unrestricted use, distribution, and reproduction in any medium, provided the original work is properly cited http://creativecommons.org/licenses/by/4.0/deed.en

Received: 20.06.2019

Accepted: 25.07.2019; Published: 28.08.2019 